\title{
Research on the Artistic Expression of Vocal Music
}

\author{
Shuyue Ding \\ School of Media \\ Mian Yang Teachers College \\ Sichuan, China 621000
}

\begin{abstract}
At present, as the main component of the vocal music art, the science of sound production should be combined with the emotion. And it is very important for the completeness of the vocal artistic expression. The science and integration of sound production is also crucial. It includes two aspects of the healthy voice and the emotional expression. Both of these functions constitute the expression of vocal art. A good vocal singer must have these specific conditions. However, in reality, it is still not enough to have only a good healthy voice. It is necessary to infiltrate into the emotional voice in the vocal art. And we could use this emotional voice to enhance the artistic expression of the vocal music. Of course, on the other hand, we should put good feeling into the vocal music. However, there is no scientific way of voicing. Without a good state of singing and related instruments, the current vocal music can't show complete performance.
\end{abstract}

Keywords-vocal music; influencing factors; physical performance

\section{INTRODUCTION}

Music, as the important science in current practice of virtue education in China, plays a very important role in promoting the entire process of vocal music. It is the combination of breath, vocal cords and resonance. And we should have a correct attitude toward singing. The singer could improve the expression of vocal music by working on the basis of the mutual relations between the breathing organ and the vocal organ.

\section{HEALThy VoICE}

\section{A. The Role of Healthy Voice in Vocal Performance}

First, we must focus on the specific status of healthy voices in singing. In other words, a singer must first have a cleaner and healthier sound. And then, the singer could get others' attention with his voice. At the same time, the singer would conquer the audience in this way. And with this healthy and pure voice, the fans would like the singer. The pure voice is the basis of vocal music. Therefore, a healthy voice is very important. Vocal sounds are produced through the throat of the body. And if the voice produced by the throat can't be heard clearly enough, the appreciative person will sound it uncomfortable. The audience will think that the voice is harsh. Then, they wouldn't appreciate the beauty of the music. For good singers, when they have the vocal concert, even if there are some related uncomfortable situations, these discomforts will not affect the purity of the sound. And these singers will try their best to deal with these related questions. They would prevent these voices from affecting the concert. All those who have heard the concerts of these professional singers are often surprised by the purity and cleanliness of their voices. In addition, the purity of the sound is important for a beginner. And the singer must pay attention to the purity of the voice as it is released.

\section{B. The Ways of Having Healthy Voice}

The pure, clean and full voice is often not formed in one morning or evening. This pure voice is achieved through constant good and efficient practice.

First, the singers must have a better state of singing. If the singers want to get good and healthy voice, they must make long-term hard-working preparation, scientific and correct exercise. They must establish more natural and relatively good state of singing before each singing. The establishment of this state mainly includes positive singing posture, clearer pronunciation and the right breath. It can be said that the correct state of breathing in the singing process is particularly self-evident. The correct breathing in the artistic expression of singing plays decisive role. Also, it is the basis and premise of singing methods. Some famous masters have always had certain commentary on the importance of proper breathing. Many people can't use the correct breathing. And it causes the singing deficiency and problems. In this condition, it asks the singers to make the exploration on establishing reasonable and correct breath during the singing process. The importance of breathing in singing is fully recognized. At the same time, the singers should be better informed about how to get correct breathing state. First of all, the students must understand the importance of proper breathing. And they should learn to use the breath. Also, the students should pay attention to the effective and reasonable adjustment of the breath.

Second, the practice of sound production also plays an important role in the current singing environment. The practice of sound production is the most basic training for the singers in the current. And it is to develop correct scientific singing method. The main purpose of this practice of sound production is to exercise the vocal music of the singer. And to a certain extent, it could correct the system of sound production. Also, the singers would get the analysis and guidance. With this guidance, the singers would get some practice of sound production. The singers would control the breath, which can truly become the dominant position in the art expression. During the concrete practice, singers must 
learn to develop some positive and rich imagination through some of their own thoughts and ideas. Through these imaginations, the singers would have a series of contrasts and associations. Therefore, some abstraction in art can't be understood. However, it can be translated into clearly visible content. For example, the singers would use some associative metaphors. With the practice of sound production, the singers would have new understanding of the abstract concept of art. For example, the singers would use yawns to describe the singer's action to open the throat. Through the comparison of these methods, it could motivate the enthusiasm of singing learners. It can inspire the singers to make some positive thinking. And the singers could make the preparation and adjustment in time. The singers must learn the correct way to make the expression. Finally, it would achieve the purpose of coordinating the wisdom and singing content.

\section{INFLUENCING FACTORS OF THE PSYCHOLOGICAL STATE OF SINGING}

\section{A. The Factors of Singing Performance and Personality}

There are many factors that may influence performance desires in concerts, such as whether the performers really like singing, whether he really loves song or whether the singing environment is comfortable. These specific issues are mainly related to the concrete reasons or objective reasons of subjective desires for the vocal performers. These specific issues may affect the performance desire of the singers in the process of singing. And then, the artistic effect of the whole vocal performance can be influenced. Therefore, this factor is very important for the supervisors of the vocal performance. The singers of vocal performances are satisfied with their specific performance throughout the singing process. And they would feel confident. It can be said that confident singing attitude is very important for the performance of the whole concert. Another subjective factor is the personality. The personality factor is also very important. Some people are more introverted. They tend to be subject to some objective circumstances. These people tend to be more specific about the success or failure. Specifically, it would be more difficulty for these people to adjust the corresponding mentality. The other part of the crowd is outgoing. On the stage, the singers will have stronger stage performance. And they hope to express their feelings through the performances. And the emotions can make their body better participate in the singing. It would fully improve the enthusiasm in the performance. Therefore, the singers should better play their singing skills with the guidance of this emotion.

\section{B. Psychological Factors of External Pressure}

If the performers of vocal music have the pressure before performance, they would fail to perform well. In the teaching of vocal music, the performers easily get the high expectations of other people, such as teachers and parents. And these expectations from professionals and teachers would be the pressures and mental burdens easily. With these factors, the psychological pressure would increase.
Eventually, the performer would be nervous in the entire performance. Finally, to some extent, singing skills can't be guaranteed. In addition, the performers often come to the stage with some distractions. With these distractions, the performers may have stronger desire to perform after standing on the stage. And then, it would have some influences on the performing capability of the performer. During the process of performing, the performers can't put their back into it. For the whole process of the show, the performers can't be calm. And sometimes, there would have some mental distraction. Even, they can't perform well. Therefore, this external pressure has adverse effect on the performance of the performer. And it would easily lead to the failure of entire performance. Therefore, in the whole process of singing performance, the singers must pay attention to the performance with ordinary circumstances. And then, the emotions and energies of the performer can be put into the songs. The singers would forget the distractions.

\section{Subconscious Influences}

In their singing performance, most of people are controlled and affected by subconscious minds. In this case, the subconscious is often formed with the habit. Therefore, in the performance process, they would complete the vocal performance through the subconscious mind. The singers would accomplish the specific activities of vocal performance with many parts of the body, organs and muscles related to the singing at the same time.. The human beings can only dominate one or a few organs at most for a period time. Therefore, during the usual practice of vocal performance, it is necessary to form habitual behaviors through the movement of this vocal music. At the same time, this behavior is simply controlled by the subconsciousness. Therefore, in the activity of vocal music, we should hide consciousness in the dominance. Other actions are attached to the influence of subconsciousness. In the specific training of vocal music, we must form correct and natural training and cultivate relatively good singing habits. And the subsequent singing habits can be conducive to singing career.

\section{Physical PERformances ARE NECESSARY COMPLEMENT TO VOCAL EXPRESSION}

\section{A. Body Posture}

Singing as the expression form of entire beauty is an important way to bring beauty to the world. Therefore, the primary responsibility of vocal music actors is to create the beauty. In singing, the beauty of gesture refers to beautiful look or beautiful figure and elegant temperament. Also, the most important thing is the beauty of the behaviors. The tall and straight physical form can make the sound production of singing be improved. Also, it can establish better stage image In addition, it can also cultivate the temperament and stage manner. The singers would mainly perform the posture of the body based on the content and style of the songs. Through different body positions, they can show the different forms of art. In addition to some lyric songs, the singers can also add some elements of hip-hop to the fastpaced songs. It must be emphasized that in the process of 
performance, no matter the types of songs or the length of song it is, no matter when and wherever it is, no matter what kind of emotion need to be expressed, even to express pain and sadness, the singers should also show elegant and calm movement. And they can't use random attitude towards life. The singers' bodies must maintain curvaceous beauty. And each action should be performed with the sense.

\section{B. Facial Expressions}

In addition to the language, facial expression is also a concrete way to express human emotions. And it is the most direct way to express human emotions. Facial expression is also very important expression factor throughout vocal performance. Sometimes, these facial expressions are even more important than the language of the song. These facial expressions would be more intuitive and visual than the language of the song. In some ways of sound production, the facial expression must be able to stretch the eyebrows. At the same time, the smile is the most important core in the facial expressions. A smiling face can make the smile open. And at the same time, this method can make the expression look better. In addition, the voice in the entire vocal performance always maintains a higher position. The singing would always be able to maintain a positive state. The main focus of the entire facial expression lies in the eyes. It can be said that the eyes are the window of the mind of the person. People are complicated. And they can express many subtle feelings through some ways. The most obvious and important expression is to use the eyes. The actor must learn to image the situation based on the scene of the song. The eyes of the actor can fully convey the emotion. In the performance of vocal music, the singers must learn to communicate with the audience by extending his eyes to the audience. In this way, the audience can be better touched. The distance between the audience and the actor can be narrowed. In addition, this enhancement of eye expression is also a key factor in the training of the vocal performance. It plays an important role in enhancing the artistic expression of vocal music. The expressive facial expressions are very important to show the content of the song. And the audiences would have good impression.

\section{Gesture Action}

The gesture actions are important factor and the form of performance in the whole stage performance. Sometimes, the importance and the function of the performance of the song are as much as the conductor in the chorus. Gesture is the silent language in the process of expression. Gestures are concrete acts to express the sincere emotions during the performance. The gestures are used to participate in the singing. And the breath and sound can be better complemented by each other. The perfect fusion is achieved by the music. There are several main types of gestures, which are used to express the awareness of the voice and the emotion during the singing. In addition, the gesture can be more delicate throughout the singing performance. And the gestures vividly reflect the rhythm of music and the connotation of the song. In the hand movements, the singers should also make the design according to the specific contents of the songs. The singers must make careful arrangement. They must take the singing as the main content. And it can't overwhelm the main purpose of the song. Otherwise, the audience would forget the content of the songs.

\section{CONCLUSION}

In a word, vocal performance, as a kind of artistic expression that needs very strong artistic appeal. And vocal performance is affected by many aspects of vocal music form. Its artistic charm would bring people the feeling of beauty. And the audience would be attracted and infected by this vocal artistic expression. Eventually, it could convey more optimistic, beautiful and positive life attitude. And then, it would show artistic expression.

\section{REFERENCES}

[1] Li Wei. On the artistic expression of vocal music [J]. Labor and Social Security, 2014, (5): 161-161.

[2] Hao Aizhen. On artistic expression of vocal music from the perspective of singing skills [J]. Oriental Education, 2015, (6): 285285,286 .

[3] Xiao Ling. Cultivation of performing skills in the practice of vocal music [J]. Journal of South-Central University for Nationalities, 2012,32 (3): 179-180.

[4] Xie Ying. Analysis on the value of vocal skills in the vocal art [J] Talent, 2013, (30): 267-267. 